\title{
CONSELHOS PEDAGÓGICOS ATRAVÉS DA ANALOGIA DE LIDERANÇA
}

\author{
PEDAGOGICAL ADVICE THROUGH THE LEADERSHIP ANALOGY
}

\author{
Alexandre Henrique Alves de Oliveira ${ }^{1}$
}

RESUMO: O seguinte artigo tem como base de referência grandes clássicos da política e da Filosofia, elas têm em comum o fato de terem em sua essência o conselho para a liderança e sociedade, mas não se trata somente de obras propriamente cientifica, algumas são mais lúdicas como: “A Arte da Guerra” e "Quem Mexeu no Meu Queijo?" que se tornaram famosas no mundo e que foram lidas por milhões de pessoas. Utilizei delas para poder montar uma analogia entre política e educação, entre liderança e ser professor, transformar esses conselhos que foram lidos e continuam sendo lidos por grandes mentes, e lideranças, é o objetivo principal e diferencial desse artigo. Além disso foi incluindo nas pesquisas alguns clássicos da Filosofia, como também a pesquisa em algumas obras de Paulo Freire, talvez o mais importante pedagogo da História do Brasil. Para ficar mais claro esse artigo foi dividido em três partes, assim tornar-se mais especifico algumas situações que os professores podem encontrar pelo caminho.

Palavras-chave: Professor. Educação. Alunos. Liderança e igualdade.

ABSTRACT: The following article is based on great classics of politics and philosophy, they have in common the fact that they have in their essence the advice for leadership and society, but these are not only scientific works, but some are also more playful such as: "The Art of War" and "Who Moved My Cheese?" that became famous in the world and that were read by millions of people. I use them to build an analogy between politics and education, between leadership and being a teacher, transforming this advice that was read and continues to be read by great minds, and leaders are the main and differential objective of this article. In addition, some classics of Philosophy were included in the research and research in some works by Paulo Freire, perhaps the most important pedagogue in the history of Brazil. To make this article clearer, it has been separated into three parts, so that some situations that teachers may encounter along the way become more specific.

Keywords: Teacher. Education. Students. Leadership and Equality.

\footnotetext{
${ }^{\text {I }}$ Pós-graduação: Gestão, Orientação, Supervisão com Ênfase em Psicologia Educacional, PELA Faculdade Rolim de Moura (FAROL). Professor da rede pública estadual de Rondônia, professor de Filosofia e História, escolas - IEE Carmela Dutra e EEFM Prof. Eduardo Lima e Silva. Graduação: História, pela Universidade Federal de Rondônia (UNIR). E-mail: xandyhenriq@gmail.com
} 


\section{PLANEJAMENTO E ESTRATÉGIAS PARA LECIONAR BEM}

O planejamento é a maneira adequada para se preparar para a prática docente, nela que se prepara o material que vai ser usado em sala de aula; o modo como a aula vai ser exposta; ou atividade que vai ser executada; o tempo de execução das atividades planejadas; o objetivo proposto da metodologia teórica para a prática; assim como possíveis frustações que podem surgir pelo caminho.

O essencial na guerra é a vitória e não operações prolongadas. Quando ela demora a ser conquistada, as armas perdem o corte e a moral da tropa se reduz. Quando for atacar as cidades, a força do grupo estará exaurida. [...] é raro vermos uma operação inteligente que tenha sido propositadamente prolongada e, com isso, beneficiado, efetivamente, um Estado (TZU, 2005, pr8.)

Segundo o pensamento de Sun Tzu, uma ação prolongada pode ser prejudicial se não logo executada, assim também acontece na escola, com os trabalhos, ou projetos, quando são muito complexos e prolongados pode se levar a perda do interesse daqueles que participam; por exemplo, uma peça de teatro que tem objetivos didáticos: ela pode ter um bom roteiro, projeto e ideia, mas se as falas se fazem prolongadas e em demasiada quantidade, pode se levar ao desgaste dos alunos, (que por sinal são alunos e não atores), então uma peça deve ser simples, objetiva e com poucas falas, se ela se torna muito elaborada, os colaboradores podem não acompanhar o ritmo e o tempo investido não pode ter o retorno desejado, por isso os projetos, principalmente que envolve grande quantidade de pessoas tem que ter como foco agilidade para execução, como consciência de quem e o modo como vai ser executado. Entre outros pontos Sun Tzu, (2005, pi8.) Destaca:

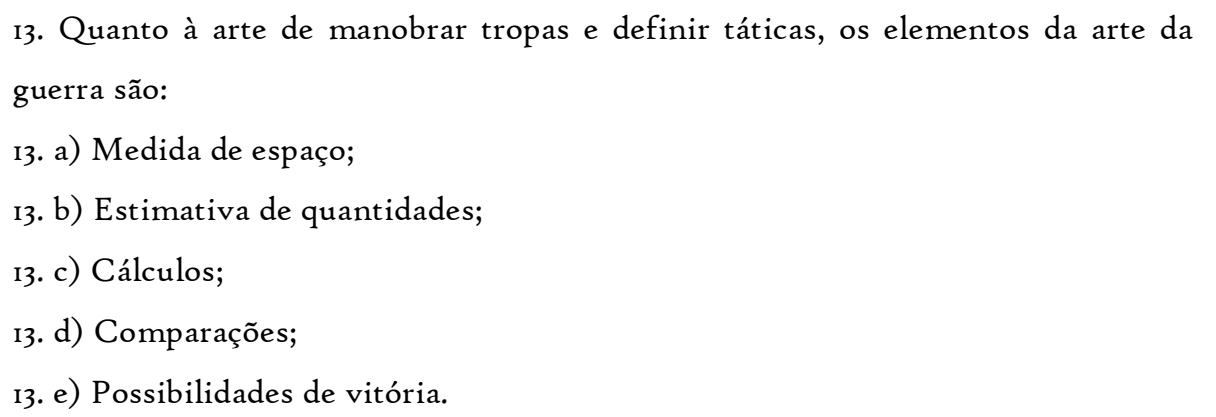

Todos esses pontos devem ser levados em consideração para que não haja nenhuma surpresa negativa, afinal planejar é se preparar. 
$\mathrm{Na}$ sociedade democrática o princípio de igualdade e defendido na nossa constituição, é como um princípio primordial ético, sobre isso Aristóteles fez a seguinte descrição:

\begin{abstract}
Embora eu tenha dito anteriormente (Capítulo II) que, por natureza, todos os homens são iguais, não se pode supor que eu me referisse a todos os tipos de igualdade. A idade ou a virtude podem dar aos homens uma precedência justa. A excelência dos talentos e dos méritos pode colocar alguns acima do nível comum. O nascimento pode sujeitar alguns, e a aliança ou os benefícios podem sujeitar outros, reconhecendo-se aqueles a quem a natureza, a gratidão ou outros aspectos possam obrigar (ARISTÓTELES, 2006, pir4).
\end{abstract}

A igualdade é o princípio da cidadania, mas as pessoas em si não são iguais, por isso ao planejarmos uma atividade ou trabalho, tem que se levar em conta a realidade dos alunos, as características da classe e vossa aptidão, querer que alunos de uma escola de periferia tenha o mesmo rendimento que alunos de escola particular com índices elevados de aprovação é errôneo sem o planejamento adequado, é o mesmo que esperar que (um time simples vença de um time milionário), a realidade é diferente, por isso o resultado será diferente. Não só de escola para escola, dentro do mesmo ambiente escolar uma turma pode ser bem mais avançada que a outra, por isso existe o nivelamento, para que o ritmo seja de acordo com a turma, porém, o tratamento deve ser o mais igualitário possível, e o desenvolvimento de uma turma deve ser trabalhado justamente para os nivelar ao melhor nível, dando com isso a oportunidade para que todos cresçam e tenham o mais próximo possível de igualdade, mesmo que para isso precise trabalhar com as falhas para se alcançar o aprimoramento.

Sem planejar tudo pode ocorrer, frustação, decepção, reações inesperadas, o planejamento se faz para a execução, mas do que isso, para a produção de qualidade, como citou Paulo Freire: “[...] Não propriamente uma reflexão crítica sobre a educação em si ou sobre a qualidade, mas em torno de educação e qualidade que nos remete à educação para a qualidade, qualidade da educação e educação e qualidade de vida", (FREIRE, p2I, 200I). Ou seja, é preciso planejar para executar com qualidade, para que haja vontade de aprender e gosto de estudar. Dando ênfase a essa afirmação também se pode notar no discurso de Maquiavel algo semelhante: "É coisa verdadeiramente muito natural e comum desejar conquistar, e sempre, quando os homens podem fazê-lo, serão levados a e não criticados; 
mas quando não podem e o fazem de qualquer maneira, aqui está o erro e a recriminação" (MAQUIAVEL, 2012, p6o). Assim o planejamento deve ser elaborado para que seja sempre da melhor maneira executado.

O planejamento assim como também, todo o resto do trabalho deve ser feito com entusiasmo, almejar o sucesso é o passo para o sucesso, de acordo com o seguinte trecho, de JONHSON, (2002, p39), fica mais claro esse pensamento: "De vez em quando, Haw imaginava Sniffe e Scurry encontrando um Novo Queijo e saboreando-o. Pensava em como seria bom aventurar-se no labirinto e encontrar um novo queijo fresco. Quase podia sentir seu sabor". do mesmo modo devemos fazer no trabalho, escola, curso, serviço, ou qualquer outra coisa que se disponha a fazer, entusiasmo e força de vontade é o motor para se começa bem o dia e um desafio, sem isso a derrota tornar-se quase evidente e as forças para prosseguir inexistente, então almeje, aspire e se entusiasme para as coisas darem certo. Acerca disso, Paulo Freire nos enseja as seguintes observações:

Ao defendermos um permanente esforço de reflexão dos oprimidos sobre suas condições concretas, não estamos pretendendo um jogo divertido em nível puramente intelectual. Estamos convencidos, pelo contrário, de que a reflexão, se realmente reflexão, conduz à prática (FREIRE, 1970, p33).

Ou seja, o planejamento não deve ser mero instrumento de documento, "para inglês ver”, ele deve ser projetado para ser executado, para ser posto em prática, mais do que isso, deve ser um instrumento para conscientização, para que o discente também seja: um serpensante, o ser-cidadão; e não somente o aluno como executor de tarefas e deveres, o planejar deve ser feito para executar, ensinar, pensar e refletir.

\section{O TRABALHO EM GRUPO, A RELAÇÃO COM OUTROS PROFESSORES}

A relação com outros professores é fundamental para um ambiente saudável de trabalho, se problemas com alunos pode causar queda, ou diminuição de produtividade, a relação com colegas de trabalho pode causar consequências semelhantes se essas são relações sociais ruins. $\mathrm{O}$ ambiente de trabalho deve ser confortável para que o indivíduo também se sinta confortável e feliz, isso não se aplica somente ao trabalho em escola, mas em qualquer relação que o trabalho é feito em grupo. Os outros professores fazem parte do 
sistema de ensino e precisamos ter uma relação agradável para que o ambiente de trabalho seja harmonioso e saudável, mesmo que a maior parte do tempo se passe com os alunos, chega um momento que a um contato com outros professores, um momento de descontração, de intervalo, de reunião, planejamento, enfim um momento que você poderá compartilha de sua visão sobre determinadas situações que somente eles podem entender.

Assim como as grandes formações abrangem as pequenas, os grandes acampamentos incluem os pequenos. O exército do front, o da retaguarda, o da direita e o da esquerda têm cada um o seu acampamento, em forma de círculo. Todos os acampamentos circundam os quartéis-generais de cada comandantechefe, montado no centro (TZU, 2005, p36.)

Nessa citação podemos perceber como cada parte pode ser importante num todo, assim também numa escola diante de tantas formações distintas e saberes diferenciados surge o embate em algumas situações sobre aquele que talvez seja o mais importante, mesmo que funcione de um modo discreto ao estilo de "preconceito à forma brasileira", mas que existe. $\mathrm{O}$ ego inflamado de um grupo intelectualmente elitizado, pelo menos em parte, pode ser explodido pela vaidade do próprio ego, cabe então que cada um se conscientize da importância de todos para o grupo, se não fossem importantes não existiriam na grade curricular, portanto é necessário ao desenvolvimento estudantil.

“Algumas vezes iam bem, mas em outras suas poderosas crenças e emoções humanas assumiam o comando e modificavam o modo como eles viam as coisas. Isso tornou a vida no labirinto mais difícil e desafiadora" (JONHSON, 2002, 25-26). Ao refletirmos sobre isso observamos, que lidar com emoções e pensamentos divergentes se torna um desafio para qualquer pessoas que se viva em sociedade, saber respeitar essa diferença faz parte da constante evolução da psique humana, que muito sofreu, guerreou e matou por ser intolerante ao outro, "Não concordo com você, mas defenderei até o fim o direito de se defender", com essa frase Voltaire exprime a essência da tolerância, a diversidade existe, ela é óbvia num país tão pluralista como o Brasil, um país eclético em religião, gênero e ideologia, essa adversidade não pode se transformar em rivalidade, cada um tem seu ponto de vista, seja político, ou ideológico, esse ponto de vista deve ser respeitado para que os ânimos estejam sempre aliviados, a consequência do desrespeito a crença e opinião pode gerar um mal estar ambiental que pode ocasionar males posterior. 
"Hem e Haw tentaram negar o que estava acontecendo, mas cada dia tinham mais dificuldade para dormir e menos energia, e se irritavam mais facilmente" (JOHNSON, 2002, p40). Essa analogia denota como algumas situações inusitadas pode ser estressante ao ser humano, estar disposto a resiliência e a tolerância, é um dos requisitos necessários para poder viver bem com o coletivo, como para sobreviver no século XXI.

"É preciso, ademais, que todo cidadão se convença de que ninguém é de si mesmo, mas todos pertencem ao Estado, e de que cada um é parte e que, portanto, o governo de cada parte deve naturalmente ter como modelo o governo do todo" (ARISTÓTELES, $\mathrm{P}_{4} 8$, 2006). A observação feita por Aristóteles, nos coloca num patamar de igualdade, todos desejamos ser amados, respeitado e tratados com equidade. Esse tratamento, portanto, deve ser reciproco, assim estabelecemos um sistema de empatia, não só tratar bem para ser bem tratado, mas também observar quem precisa ser tratado com atenção é uma forma de ação empática, muitos que vem de fora ou mesmo fazem parte do grupo se sentem desencaixados, eles precisam serem observados, esse acolhimento a aqueles que espiritualmente estão distante é uma conquista de afetividade que precisa ser feita para que o grupo fique mais forte e unido.

Mudanças no ambiente de trabalho, novas tecnologias e novos desafios - O mundo se renova tecnologicamente constantemente, novidades no ambiente de trabalho podem causar embaraços e situações desagradáveis, imposição a uma nova forma de organização ou uma nova tecnologia é comum para os que não tiveram uma formação, ou no mínimo uma orientação para o novo produto que vai ser colocado em uso, a imposição surgi principalmente entre os mais antigos que ainda não se adaptaram bem as novas tecnologias, mas se enganam aqueles que pensam que essa aversão a sistemas de novas tecnologia só ocorre entre os mais velhos, a resistência também ocorre com os mais novos, na verdade a mudança é o que espanta, a retirada do "status quo" é para alguns o mesmo que um salto no escuro ao se deparar com um rato no meio da sala. A educação e o mundo como um todo precisa de resiliência.

"Uma manhã eles chegaram ao posta $C$, e perceberam que o queijo havia desaparecido". (JOHNSON, 2002, p3I). Essa ausência do queijo nada mais é do que a representação da mudança, algumas coisas desaparecem para dar lugares a novas. "Mais 
tarde, Hem e Haw chegaram ao posto C. Não haviam prestado atenção às pequenas mudanças que ocorriam diariamente, por isso tinham como certo que seu Queijo estaria lá" (JOHNSON, 2002, p32). Se preparara para essas novas mudanças é necessário para que não seja pego de surpresa, e despreparado para o que possa ocorrer.

A formação continuada defendida pelas secretarias de educação, deve ser implantada e trabalhada junto aos professores, os mesmos devem estar dispostos a aceitação dessas novas mudanças, é preciso em muitas situações mudar para melhorar.

\footnotetext{
Haw tinha consciência de que estaria em melhor forma agora se tivesse lidado com a mudança muito antes e saído do Posto $\mathrm{C}$ mais cedo. Teria se sentido mais forte física e espiritualmente, e poderia ter enfrentado melhor o desafio de encontrar um novo queijo. De fato, provavelmente já o teria encontrado se tivesse esperado a mudança, em vez de perder tempo negando que ela ocorrera (JOHNSON, 2002, p7o).
}

O surgimento das novas tecnologias é inevitável, estar disposto a aceita-las o quanto antes só diminui uma tensão desnecessária.

As vezes o problema de relacionamento não seja os outros, talvez seja você mesmo, (é mais fácil o erro está em um, do que em todos). "Ofendendo a cada um dos habitantes e transformando todos em seus inimigos; e quem lhe pode prejudicar são os inimigos, que permanecem derrotados, em sua própria casa” (MAQUIAVEL, 2012, p56). Com esse argumento, analisamos que temos que ser amigáveis com as pessoas ao nosso redor, plantar o bem para colher o bem. Policiar-se não faz mal, principalmente se é para reparar as pontas soltas que afeta os outros e principalmente a si mesmo, pois todo ação causa uma reação, e ações nocivas tendem a também serem nocivas, por isso, buscar ser o mais agradável possível com as pessoas ao redor pode gerar bons resultados, as vezes basta um bom dia respondido, ou uma resposta dada a uma simples pergunta para se conquista o afeto e respeito de outrem, afinal de contas nunca se sabe o dia de amanhã.

\section{A RELAÇÃO PROFESSOR/ALUNO}

A última parte desse artigo refere-se à situação prática em sala de aula e a relação professor/aluno, com certeza a parte mais complicada para a maioria que exerce o trabalho como professor, é o contato direto entre professor e aluno; é esse contato que o diferencia de uma máquina ou livro, e desse contato que o aluno esclarece as dúvidas, participa, 
interagi e se envolve de maneira mais profunda com o ensino, a educação não é só aprender o que é didático e também formar cidadãos conscientes, crítico e ser-pensante, para que possam tornar a sociedade o melhor possível, mas esse contato pode ter pelo caminho algumas dificuldades. Dificuldades causadas pela complexidade da mente humana que cada indivíduo pode ter, pela diversidade social, indisciplina e falta ou insuficiência de autoridade por parte do professor, por isso, a última parte ficou dividida em subpartes para que melhor pudesse ser analisada.

I- Diversidade - No contexto de complexidade humana tratamos também da diversidade cultural e social. Diversidade no sentido mais genérico da palavra é tudo aquilo que é diferente numa determinada classe ou comunidade, e a diversidade se apresenta de forma natural por ser o próprio ser humano um ser natural e complexo, a complexidade de entender ou se relacionar com a mente humana é um problema, melhor dizendo, uma dificuldade que existe desde os tempos dos primórdios, tudo porque cada ser tem sua vontade, vontade essa que potencializada pode em muitas situações entra em choque contra o interesse de outrem, sem ter muito o que fazer contra o inevitável, o que resta a uma sociedade e saber se relacionar entre si de forma que haja o mais possível de ética e respeito entre aqueles são membro do mesmo círculo, não cabe aqui ainda a inserção da diversidade cultural e social, essa é só uma variante maior do que é a relação social. Relacionamento social é a interação entre indivíduos que existem dentro do mesmo ciclo, esse relacionamento pode gerar atrito entre os indivíduos, pelo cheque de interesse desses próprios indivíduos, afinal não a como evitar o inevitável, somente se preparar.

O sujeito que decide seguir na vida a carreira de professor, passa a ser um sujeito que inevitavelmente vai se deparar com situações desse tipo, numa sala de aula por exemplo: o agrupamento de pessoas com interesses próprios, e coletivos, inseridos dentro do mesmo ambiente, pode por algum motivo encontrar resistência em opinião ao outro, ou um atrito causado pela diversidade que plana pelo ambiente. Nessa situação temos dois pontos que agrava o que pode ser problema, como também pode ser um benefício ao aprendizado se trabalhado da maneira correta, a questão de diversidade cultural/social, num país tão extenso e pluralista como o Brasil, deve ser tratado como um benefício. Essa diversidade se faz presente cada mais pela interação entre os indivíduos de diversas 
regiões, localizações e cultura. Assim pensar que lecionar seja simplesmente ensinar, esquece que lecionar também é lidar com inúmeras opiniões, pensamentos, críticas, credos e ideologias.

Começamos o aprofundamento dessa análise, pela descrição de JONHSON (2002, p24)., "Embora os ratos e duendes fossem diferentes, tinham algo em comum: todas as manhãs vestiam roupas de correr e tênis, saíam de suas pequenas casas e corriam para o labirinto à procura de seus queijos favoritos”. Assim somos seres sociais, nos arrumamos, nos preparamos e nos encontramos num determinado ambiente para comungar dos mesmos interesses, é isso o que ocorre nas instituições, seja trabalho, escola ou algo semelhante. Então antes de tudo temos que levar em conta sobre a afirmação de Johnson, e compreendermos que atrás daqueles uniformes, existem pessoas que tem uma vida fora daquele espaço, e que essas vidas podem trazer em suas mentes problemas e conflitos internos e pessoais que são além daqueles que elas vão encarar no dia-dia de sala de aula. Através da analogia tirada da afirmação de Sun Tzu, podemos compreender um pouco mais sobre o conceito de diversidade.

Portanto, num país hostil, tudo precisa ser completamente conhecido: montanhas, rios, terras altas e baixas e colinas que ele pode defender como pontos estratégicos; florestas, canaviais, matagais e pastos luxuriantes que servem de esconderijo; as distâncias de estradas e atalhos; o tamanho das cidades e vilarejos, a extensão das vilas; a fertilidade ou aridez dos campos; a profundidade das obras de irrigação; a quantidade de provisões; e o tamanho do exército inimigo e a qualidade das armas (TZU, 2005, p35.)

Toda empreitada exige cuidado, afinal de contas o caminho a ser percorrido pode apresentar adversidades inesperadas que poderiam ser trilhados mais facilmente se tivessem tomado as precauções devidas. Portanto, numa escola temos que ter em mente todos os obstáculos que podem ser encontrado: qual o tipo de clientela daquele lugar; qual o método de trabalho daquele ambiente; o sistema de ensino; as dificuldades do grupo docente; os desafios que aquele público precisa superar; as vezes por um ou dois alunos, todo o planejamento ou parte dele precisa ser modificado, não só planejado como executado, afinal o princípio de igualdade é o que regi nossa Constituição e o que também se prega nas instituições de ensino. 
São apenas cinco as notas musicais; contudo, as melodias que estas produzem são tão numerosas que é impossível ouvir a todas. São apenas cinco as cores primárias, entretanto, as combinações que produzem são tão numerosas que é impossível visualizar a todas. São apenas cinco os sabores, mas suas misturas são tantas que é impossível provar a todas. Na batalha, temos situação idêntica: temos somente forças normais e extraordinárias, mas suas combinações não têm limites; ninguém pode compreender a todas, (TZU, 2005, p26.)

Ao analisar essa afirmação podemos ver a diversidade como algo positivo e até mesmo poético; ao observamos o contraste apresentado percebemos quão belo pode ser isso é trabalhado da maneira correta. "Assim como ratos, os dois duendes, Hem e Haw, também utilizavam sua habilidade de pensar e aprender com experiências passadas. Entretanto, contavam com seus complicados cérebros para desenvolver métodos mais sofisticados de encontrar o Queijo" (JOHNSON, 2002, p25). Identificando essa afirmação para complemento do parágrafo iniciado, podemos concluir que o contato com aquilo que é diferente, aquilo que é fora do costume, pode ser proveitoso no sentido de aprendizado, com essas experiências e vivências podemos ampliar nosso conhecimento de maneira prática, ampliar nossa visão de mundo, compreender a tolerância, e combater o preconceito de forma prática e realista.

2- $\quad$ Autoridade como professor - Essa é sem dúvida a parte mais desafiante em lecionar, ter o contato com os alunos e saber usar da autoridade outorgada. Ensinar e semelhante a liderar, aquele que lidera coloca-se a ser ouvido e seguido, aquele que ensina faz o mesmo, o professor é um símbolo de conhecimento, detento do saber: que orienta, jovens e adultos para o mundo.

\footnotetext{
Assim podemos enfatizar com a seguinte afirmação de como é a própria virtude que, em nosso sistema, faz o bom cidadão, o bom magistrado e o homem de bem, e como é preciso começar obedecendo antes de comandar, o legislador deve cuidar principalmente de formar pessoas honestas, procurar saber por quais exercícios tornará honestos os cidadãos e sobretudo conhecer bem qual é o ponto capital da vida feliz (ARISTÓTELES, 2006, p42).
}

Porém, esse papel não é tão simples, ele tem que passar por situações que muitas vezes se fazem constrangedores, a função do professor é justamente de manter as coisas em ordem, e fazer o sistema funcionar de maneira correta. Ele é o combatente do agente do caos, tanto na teoria como na prática, mas como todo agente ele precisa se posicionar e mostrar em que lado ele está, muitos professores se perdem pela falta de confiança e 
autoridade, e outros pela falta de controle dado a liberdade exacerbada que se confundi com libertinagem por parte dos alunos.

Que ninguém se espante se eu alinhar exemplos extraordinários, ao falar de
principados completamente novos, tanto príncipe como de estado; pois, ao
caminhar quase sempre pelas vias desbravadas por outrem e os imitar, e como
não é possível completamente imitar a via de outrem, nem atingir a virtude
daquele que se imita, deve um homem prudente percorrer sempre a via dos
grandes homens, aqueles que são excelentíssimos para imitar, de forma que, se
não chega a ti a virtude deles, ao menos chegará algum odor; e deve fazer com os
melhores arqueiros, os quais, quando o alvo parece muito distante, e conhecendo
a virtude de seus arqueiros, colocaram a mira bem acima do alvo, não para lançar
a flecha a essa altura, mas poder com a ajuda dessa mira alta, atingir o alvo
(MAQUIAVEL, 2012, 72).

Nessa observação podemos destacar como ponto de analise o papel do professor como forma de liderança, ele tem que ter um Norte, alguém que sirva como espelho, pelo menos parcialmente, não necessariamente precisa ser uma única pessoa, mas pode ser mais de uma, isso é importante para aqueles que muitas das vezes são iniciantes, ou para aqueles que já iniciaram e sentem que precisam melhorar, recomeçar; todo grande artista tem uma inspiração, assim como toda a liderança, o mais importante nessa observação é saber ter alguém como referência caso não esteja conseguindo seguir por seus próprios fundamentos, mas desde já que fique claro que de modo natural todos acabam de um modo ou de outro seguindo um modelo para a prática da docência, é nesse modelo que encontramos os pontos positivos, e as artimanhas que mantém a segurança, e confiança de prosseguir na docência de maneira mais correta. Enfim, também destaca na analogia a questão das flechas e o alvo, é preciso que tenha um objetivo, esse objetivo vai estar na metodologia que tende a criar um impacto aos lecionados, impacto esse que deve ser positivo, e acima de tudo proceder de maneira ética.

Um dos problemas que os professores enfrentam é a insegurança de ter que lidar com pessoas, não só acontece com os professores, muita gente que lida com o público sente insegurança ao trabalhar com o público, mas ter medo de pessoas é infundável nessa profissão, (é como querer ser cirurgião e ter medo de sangue), as pessoas são o público e o público sente a insegurança daqueles que vos fala, perceba pela fala de JOHNSON:

Haw sentiu que sua força física diminuía. Sabia que estava perdido e tinha medo de não sobreviver. Pensou em dar meia-volta e se dirigir ao Posto C. Uma vez que, Hem estava lá, se conseguisse voltar, pelo menos não ficaria sozinho. Então 
se fez novamente a mesma pergunta: $O$ que você faria se não tivesse medo? (JOHNSON, 2006, p54).

Essa parte JOHNSON destaca a reflexão feita por um dos personagens centrais, “o que faria se não tivesse medo?”, esse medo que domina em alguns caso é o que mais impedi de se fazer um bom trabalho, um humorista por exemplo, ele tem que ter segurança suficiente para fazer uma piada, ele precisa confiar na interpretação dele, sentir que o que diz é engraçado, se ele não passa essa confiança as pessoas não se sentem contagiada com o humor do texto que ele utiliza, o professor é a mesma coisa, a segurança de discursar, é percebido nas palavras, e somente com segurança se passa confiança e credibilidade.

A segurança na hora de lecionar é um dos pontos chave para o sucesso da transmissão do conhecimento, mas ela não defini a autoridade por completo do docente, apesar dela ser o ponto forte para evitar que o público o critique, ela é insuficiente como autoridade, para se ter autoridade é preciso exerce essa autoridade, o professor tem esse poder e deve usar quando necessário, se não pode perde o controle do grupo, o que leva ao descrédito como profissional e pouco aproveitamento por parte daqueles que querem aprender.

No início do reinado de Ch'ang Ch'ing, T'ien $\mathrm{Pu}$ recebeu o comando em Wei com a finalidade de atacar Wang T'ing-ch'ou. Pu tinha crescido em Wei, onde as pessoas não o respeitavam; foi incapaz de conter os vários milhares de homens cavalgando em burros pelo acampamento. Depois de permanecer em sua posição por vários meses, desejou batalhar, mas os oficiais e tropas se dispersaram. Desesperado, Pu suicidou-se (TZU, 2005, p43).

Essa comparação nos mostra como a falta de autoridade e de posicionamento pode leva ao descontrole, um professor que não tem controle de turma é uma derrota não só para a educação, mas para ele mesmo. "Haw teve de admitir que o maior obstáculo à mudança está dentro de você mesmo, e que nada melhora até você mudar" (JOHNSON, 2002, p74). assim conclui-se que nada está perdido por completo, se for preciso mude.

Passemos agora para um outro ponto que é problemático e oposto ao anterior, a autoridade que foi transviada em autoritarismo, uma das características dos professores antigo e que ainda existe é o autoritarismo como forma de ensino, muitos achavam que esse era o caminho correto, mas sabe-se hoje em dia que o mais importante é cativa e conquista à atenção do aluno, do que impor o medo para obter retorno, autoritarismo 
muitas das vezes pode gerar repulsa e desinteresse do aluno, isso não ocorre de um dia para outro, mas é contaminante com o passar dos tempos. Prosseguimos com a seguinte afirmação de Sun Tzu (2005, pr8): "É chamado de enganoso o terreno do qual é fácil sair, mas difícil retornar. Sua natureza é tal que, caso se faça uma investida contra o inimigo, mas não se vença, de imediato, a batalha, o retorno a esse terreno é difícil. Tal situação não é proveitosa”. Identificamos então, que na educação o mais difícil talvez não seja dominar o conteúdo, o domínio do conteúdo tem que ser tão natural ao professor como a música para o artista, o que se ensina é conteúdo, porém não só isso basta, para lecionar é preciso também saber cativar, isso é o obstáculo principal a ser vencido por qualquer um que escolha trabalhar com o público, tanto porque o conteúdo é algo escolhido pela aptidão de quem decidiu ser professor, já lecionar é o que torna o desafio mais complicado, é o motivo pelo qual a maioria desiste no estágio, porque é quando a realidade do sistema de educação passa a ser encarado, por isso o modo como se conduz uma turma deve ser feito de forma cuidadosa por quem ensina.

Note-se que, ao tomar um estado, deve o ocupador relacionar todas as ofensas que precisa fazer; e fazê-las todas de uma só vez, para não ter de renová-las a cada dia e, não renovando, reassegurar os homens e cativá-los com benefícios. Quem de outra maneira procede, por timidez ou maus conselhos, precisa ter sempre a faca na mão; nunca poderá confiar em seus 'súditos e estes, pelas injúrias contínuas e recentes, tampouco confiarão nele (MAQUIAVEL, 2002, p9o).

Identifica-se aqui justamente um ponto de ligação do que foi referido no parágrafo anterior a esse, o fato de ter que adverti é próprio da autoridade do professor que precisa manter o controle e o bom desempenho do aluno, mas nota-se que deve ser feito de modo pontual, e objetivo, sem momentos constantes para não haver o desgaste do carisma diante aos alunos, sem transforma essa advertência num problema, mas usá-la para extrair as causas danosas que prejudicam a turma, extraindo-a, mostra a verdadeira natureza da autoridade do professor que a construção de uma metodologia correta e ética.

Enfim, chegamos ao meio termo, a aplicação da autoridade de maneira equilibrada. Para encerrar essa parte utilizarei um trecho da obra de Locke, que define a lei para o bem da sociedade e o conceito de liberdade.

A lei, em sua verdadeira noção, não é tanto a limitação, mas a direção de um agente livre inteligente em seu próprio interesse, e só prescreve visando o bem 
comum daqueles que lhe são submetidos. Se eles pudessem ser mais felizes sem ela, a lei desapareceria como um objeto inútil; não é confinando alguém que lhe tornamos inacessíveis os lodaçais e os precipícios. De forma que, mesmo que possa ser errada, a finalidade da lei não é abolir ou conter, mas preservar e ampliar a liberdade. Em todas as situações de seres criados aptos à lei, onde não há lei, não há liberdade. A liberdade consiste em não se estar sujeito à restrição e à violência por parte de outras pessoas; o que não pode ocorrer onde não há lei: e não é, como nos foi dito, uma liberdade para todo homem agir como lhe apraz. (Quem poderia ser livre se outras pessoas pudessem lhe impor seus caprichos?) Ela se define como a liberdade, para cada um, de dispor e ordenar sobre sua própria pessoa, ações, possessões e tudo aquilo que lhe pertence, dentro da permissão das leis às quais está submetida, e, por isso, não estar sujeito à vontade arbitrária de outra pessoa, mas seguir livremente a sua própria vontade (LOCKE, 200I, pirs).

Entendemos a lei como a imposição do professor em não aceitar a indisciplina da classe que leciona. Num primeiro momento Locke aponta a lei como forma de assegurar a liberdade, no caso do professor e fazer cumprir as regras de uma boa conduta por parte dos alunos, justamente para o bem dos alunos, a lei nessa situação é a representação dos limites que precisam ser impostos para que não haja bagunça, desordem ou desrespeito. No segundo momento descreve a liberdade para ser desfrutada em consideração aos outros que ali convivem, se todos fazem o que querem acabam prejudicando àqueles que não querem que isso acontece, nesse sentido a liberdade de uns aflige a outrem, passa então a ser prejudicial a outrem, entretanto se todos gozam dos mesmos princípios de igualdade e seguem os limites necessários de um ambiente harmonioso e ético, logo todos poderão ser livres de modo igual, a liberdade de um aluno consiste em viver bem de acordo com aqueles que fazem parte do seu ambiente escolar, essa liberdade deve ser desfrutada no sentido de falar, se expressar, reivindicar, e não em atrapalhar, ofender ou distorcer o princípio fundamental da educação que é o ensino.

3. Atividades, trabalho e avaliação - Enfim, chegamos à parte das atividades, o professor é o orientador do ensino para o desenvolvimento do aluno, eles precisam fazer atividades, trabalho, avaliações, precisam participar, para poderem serem avaliados, é dessa forma que sabemos em que nível de aprendizado eles estão, se tem conhecimento didático para evoluir de turma. É a forma de comprovarem que realmente estão aprendendo, e que o desenvolvimento deles realmente esteja acontecendo.

Uns não dão nenhuma importância aos cargos políticos e consideram a vida de um homem livre muito superior à que se leva na confusão do governo; outros 
preferem a vida política, não acreditando que seja possível não fazer nada, nem portanto ser feliz quando não se faz nada, nem que se possa conceber a felicidade na inação (ARISTÓTELES, p35, 2006).

Fica claro o que é discutido aqui é o simples fato de participarem e de não participarem, alguns acreditam que não precisam participar de atividades porque acreditam que seja inútil, ou que possam passar sem elas, ou simplesmente não as fazem por se negarem a fazer, mas cabe ao professor destaca a importância disso e procura ajudar para a participação do alunado, o professor é acima de tudo também um facilitador.

Assim, no emprego de homens, o método é usar o avarento e o estúpido, o sábio e
o corajoso, dando-lhes responsabilidades nas situações que melhor se ajustem a
eles. Não se pode encarregar pessoas de algo que não sabem fazer. O correto é
selecioná-las e dar-lhes responsabilidades, conforme suas aptidões (TZU, 2005,
p28).

Aqui temos uma situação de conceber aquilo de acordo com a capacidade daqueles a quem foi concebido, ou seja, conhecer a realidade daquele ambiente para que se possa trabalhar com aquele público, isso foi dito na parte do planejamento, porém deve ir além disso, tem que saber conquistar o alunado para que todos possam participar, o uso da coerção pode gerar produção, porém precisamos gerar valores e interesse em fazer de forma que não seja somente pelo interesse da aprovação, mas também pela curiosidade de querer aprender, fazer com que o máximo possível de alunos participem, não deixando de usar métodos diferenciados, em que eles possam demonstrar seu potencial, o importante de ensinar e fazer aprender, e demonstrando que esse aprendizado foi adquirido, o professor cumpriu com a sua missão.

\section{REFERÊNCIAS BIBLIOGRÁFICAS}

ARISTÓTElES. Política. São Paulo, SP. $6^{\circ}$ edição. Ed. Martin Claret. 2006. Disponibilizada pela equipe Le Livros, dados de COPYRIGHT.

BRASIL. [Constituição (1988)]. Constituição da República Federativa do Brasil de 1988. Brasília, DF: Presidência da República, [2016]. Disponível em: http://www.planalto.gov.br/ccivil_03/constituicao/constituicao.htm. Acesso em Dezembro de 2021. 
FREIRE, Paulo. Pedagogia do Oprimido. Rio de Janeiro, RJ. $17^{\circ}$ edição. Ed. Paz e Terra. 1970.

FREIRE, Paulo. Política e educação - Ensaios. São Paulo, SP. $5^{\circ}$ edição. Ed. Cortez 200 . (Coleção Questões de Nossa Época; v23).

JOHNSON, Spencer. Quem Mexeu no Meu Queijo; tradução de Maria Clara de Biase. $31^{\circ}$ ed. - Record - Rio de Janeiro: 2002

LOCKE, Jonh. Segundo Tratado Sobre Governo Civil. Petrópolis, RJ. $3^{\circ}$ edição. Ed. Vozes. 2001.

MAQUIAVEL, Nicolau. O Príncipe. Traduções e Notas, Leda Beck. São Paulo, SP. Ed. Martin Clarte. 2012. (Coleção a obra-prima de cada autor; 2).

SUN-TZU, século VI a.C. A Arte da Guerra: Por uma Estratégia Perfeita. Tradução Heloísa Sarzana Pugliesi, Márcio Pugliesi. - São Paulo, SP. Ed. Madras. 2005. 